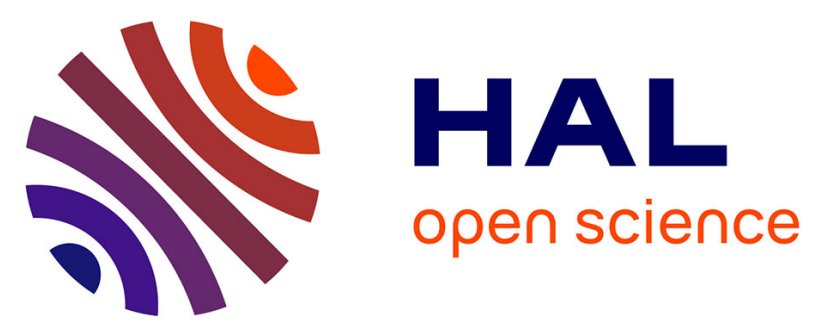

\title{
IN-SITU PROCESSING OF CARBON COATINGS ON THE SURFACE OF SiC-BASED FIBERS
}

Adrien Delcamp, Laurence Maillé, Benoit Rufino, Stéphane Mazerat, René Pailler, A. Guette, P. Weisbecker, H. Plaisantin, Eric Philippe, S. Loison

\section{To cite this version:}

Adrien Delcamp, Laurence Maillé, Benoit Rufino, Stéphane Mazerat, René Pailler, et al.. IN-SITU PROCESSING OF CARBON COATINGS ON THE SURFACE OF SiC-BASED FIBERS. Surface and Coatings Technology, 2010, 205 (3), pp.703 - 709. 10.1016/j.surfcoat.2010.07.060 . hal-01845301

\author{
HAL Id: hal-01845301 \\ https://hal.science/hal-01845301
}

Submitted on 20 Jul 2018

HAL is a multi-disciplinary open access archive for the deposit and dissemination of scientific research documents, whether they are published or not. The documents may come from teaching and research institutions in France or abroad, or from public or private research centers.
L'archive ouverte pluridisciplinaire HAL, est destinée au dépôt et à la diffusion de documents scientifiques de niveau recherche, publiés ou non, émanant des établissements d'enseignement et de recherche français ou étrangers, des laboratoires publics ou privés. 


\title{
IN-SITU PROCESSING OF CARBON COATINGS ON THE
}

\section{SURFACE OF SiC-BASED FIBERS}

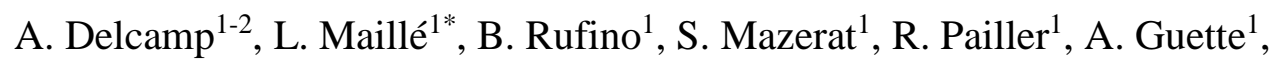

\author{
P. Weisbecker ${ }^{1}$, H. Plaisantin ${ }^{2}$, E. Philippe ${ }^{2}$, S. Loison ${ }^{2}$ \\ ${ }^{1}$ Université Bordeaux 1 - UMR 5801, LCTS, 33600 Pessac, France \\ ${ }^{2}$ Snecma Propulsion Solide, 33185 Haillan, France
}

\begin{abstract}
Carbon coatings have been formed on the surface of free carbon containing Tyranno ZMI and Nicalon SiC-based fibers by reaction with chlorine gas (chlorination) in the temperature range $550-675^{\circ} \mathrm{C}$. The kinetics and growth mechanisms have been investigated for both fibers. Results have shown that, for similar experimental conditions, the reactivity of both fibers displayed noticeable discrepancies. It has thus
\end{abstract} been observed that the Nicalon fiber was more prone to chlorine-based treatment and displayed a thicker carbon coating than the ZMI fiber. These results have also revealed that, in both case, these thicknesses can be closely monitored by physical parameters such as temperature and aging duration. The nature of the obtained coating has also been investigated by various experimental devices. AES, SEM and TEM analyses have thus evidenced that these carbon coatings were uniform and well adherent whereas AFM showed that the chlorine-based treatments resulted in a nanometer-range roughness at the fiber surface. Adsorption gas analyses also revealed a microporosity coupled with a high specific surface area. The chemical composition of the final products was determined by XPS and Mass Spectroscopy. Finally, the oxidation behaviour which was investigated by thermogravimetric analysis revealed that oxidation occurs at a quite low temperature $\left(225^{\circ} \mathrm{C}\right)$.

Keywords: Carbon; Fibres; Porosity.

*Corresponding author: maille@lcts.u-bordeaux1.fr (L. Maillé), tel: 33-5-5684-4736, fax: 33-5-5684-1225 (LCTS, 3 allée de La Boetie, 33600 Pessac, France). 


\section{Introduction}

Both their high toughness and non-catastrophic failure behavior render ceramic matrix composite (CMCs) attractive for high temperature structural applications [1-2]. SiCbased fibers have long been considered as the main candidates to provide reinforcement in CMCs because of their high tensile strength, high elastic modulus, good oxidation resistance and thermal stability [3]. The advantage of interposing a compliant coating, most often carbon, between the fiber and the matrix in order to provide an adequate bonding and a fair protection of the fibers has also long been established [4-5]. More recently, research works have focused on the in-situ synthesis of these compliant coatings through various treatments.

Some authors [6-7] have thus studied the direct synthesis of carbon coating on $\mathrm{SiC}$ based Tyranno ZMI fiber surface, on $\mathrm{TiC}$ and/or $\mathrm{ZrC}$ powder surfaces [8-10], as well as on $\mathrm{SiC}$ ceramics [11-12], by chlorine etching. However, no similar studies on standard Nicalon fibers which are of great interest for CMC's applications because of their lower cost and easy availability have yet been reported. This carbon coating should posses all the following distinct features: to provide an individual and uniform coating around the fibers, while avoiding bonding between them; to be stable during the processing of the matrix and of the interphase; to present a good adhesion with both the fibers and the interphase; and to preserve the mechanical properties of the fibers. The objectives of the present work were (i) to study the growth carbon coatings obtained from chlorine etching on the surface of both ZMI and Nicalon fibers (by establishing kinetic laws, correlating these kinetic laws with the nature of the fiber), (ii) to characterize the morphology and the chemistry of these carbon coatings, and (iii) to study their oxidation behavior. 


\section{Materials and experimental procedure}

Two different kinds of SiC-based fibers have been used in the present study: Tyranno ZMI from UBE Industries and Nicalon NLM-202 from Nippon Carbon. After having been desized, these SiC-based fibers were treated under an atmospheric pressure of pure chlorine with a gas flow rate of $500 \mathrm{sccm}$ in the temperature range $550-675^{\circ} \mathrm{C}$. The experimental device used for chlorination is represented in figure 1 . The chlorine rate was always kept in excess in order to avoid a possible gas depletion. $\mathbf{A} \mathbf{~ N a O H}$ allows to capture $\mathrm{Cl}_{2}$ at the exit of the furnace, according to the following chemical reaction 1:

$\mathrm{Cl}_{2}+4 \mathrm{NaOH} \rightarrow 2 \mathrm{NaCl}+2 \mathrm{NaClO}+2 \mathrm{H}_{2} \mathrm{O}$ equation 1

The chemical compositions of the as-received fibers are reported in table1. Scanning Electron Microscopy (SEM Hitachi S 4500) and Atomic Force Microscopy (AFM Digital Instrument 3100) characterizations were performed to measure the carbon coating thickness and to characterize the surface morphology (in tapping mode), respectively. The coating microstructure was studied with a Philips CM30ST (LaB6, 300kV) Transmission Electron Microscope (TEM), using samples prepared by mechanical thinning to $20 \mu \mathrm{m}$ and ion milling (Gatan Dual Mill). Chemical composition was determined in depth profile by Auger Electron Spectroscopy (VG Microlab 310F) coupled with argon ion sputtering at $4 \mathrm{keV}$. Gas sorption analysis was carried out using nitrogen as test gas with a commercial instrument (ASAP 2010 from Micromeritics) at $196.15^{\circ} \mathrm{C}$. Prior to the analyses, the samples were cleaned at a low pressure (i.e. $<10^{-4}$ $\mathrm{Pa}$ ) at $120^{\circ} \mathrm{C}$ for 15 hours. The Specific Surface Area (SSA) was calculated using the Brunauer-Emmet-Teller (BET) equation. The size distribution and the volume of the pores were calculated using the semi-empirical Horvath and Kawazoe (HK) approach [13]. 
Thermo Gravimetric Analysis (TGA 24 from SETARAM) was used to study the oxidation kinetics of the carbon coatings under dynamic dry oxygen atmosphere (60 $\mathrm{mL} \cdot \mathrm{min}^{-1}$ ) within a temperature range of $225-400^{\circ} \mathrm{C}$.

Chemical analyses of volatile species were performed by mass spectrometry with a commercial instrument (QMS 200 GSD 301 T2 Thermostar) under dynamic Helium flow $\left(60 \mathrm{~mL} \cdot \mathrm{min}^{-1}\right)$ within a temperature range of $20-950^{\circ} \mathrm{C}$ using a ramping rate of 20 ${ }^{\circ} \mathrm{C} / \mathrm{min}$.

X-ray Photoelectron Spectroscopy (XPS) characterizations were performed with a commercial instrument (VG Escalab 220i XL) in order to detect possible absorbed contaminations at the carbon surfaces.

\section{Results and discussions}

\subsection{Chlorine etching process}

Carbon coatings were synthesized at the surface of the SiC-based fibers by the extraction of $\mathrm{Si}$ from the $\mathrm{SiC}$ phase by chlorine according to the following chemical reaction [7]:

$\mathrm{SiC}(\mathrm{s})+2 \mathrm{Cl}_{2}(\mathrm{~g}) \rightarrow \mathrm{SiCl}_{4}(\mathrm{~g})+\mathrm{C}(\mathrm{s})$ equation 2 As already mentioned in the preceding section, two temperatures, $600^{\circ} \mathrm{C}$ and $650^{\circ} \mathrm{C}$, have been considered for these chlorine-based treatments whereas their durations where varied between 20 to 220 min. Figure 1 displays the average thickness of the carbon coatings thus obtained for both the ZMI and Nicalon fibers as a function of the chlorine etching time.

It may be observed that these thicknesses increase linearly with the treatment duration. Conseqently, the following growth rate may be proposed:

$\mathrm{e}=\mathrm{k} \cdot \mathrm{t}$

equation 3 
Where $\boldsymbol{e}$ is defined as the carbon thickness $(\mathbf{n m}), \boldsymbol{k}$ denotes the reaction rate $\left(\mathbf{n m} . \mathbf{m i n}^{-\mathbf{1}}\right)$ and $\boldsymbol{t}$ is the treatment duration ( $\mathbf{m i n})$. Correlatively to the data displayed in figure 2 , it may be seen that the Nicalon fibers are prone a reaction rate much higher than that of the ZMI fibers.

Besides, the linearity of the kinetic laws suggests that the carbon coating growth is in any case controlled by a surface reaction mechanism, i.e. the diffusion of the reactant species through the layers apparently does not act as a limiting factor. As a result, the carbon coating thicknesses is homogeneous (figure 3), and can be closely controlled by the experimental parameters such as temperature and duration.

An Auger Electron Spectroscopy (AES) depth-profile analysis of a ZMI fiber having a carbon coating thickness of $700 \mathrm{~nm}$ has been achieved in order to check the chemical composition of the coating (figure 3a). It may be seen, from figure 4, that both the carbon coating and the fiber core are clearly distinguishable. Results of the AES analysis have confirmed that the coating is solely composed of carbon, i.e. no traces of either silicon or oxygen were detected within the layer. Although, chlorine was not observed, it may be inferred it was likely present in the coating, because, during the Auger Spectroscopy analysis, ion sputtering should have desorbed the adsorbed species. The thicknesses of the carbon coatings derived from AES analysis are in good agreement with the SEM observations. Figure 5 thus shows the growth rates of the carbon coatings as a function of the chlorine etching temperature for a constant treatment time of 45 min.

For both fibers in temperatures range $550-675^{\circ} \mathrm{C}$, the growth of carbon layer obeyed to Arrhenius law $\left(\mathbf{k}=\mathbf{k}_{0} \mathbf{e}^{-\mathbf{E a} / \mathbf{R T}}\right)$, where $\mathrm{k}_{0}$ is the pre-exponential factor, $\mathrm{E}_{\mathrm{a}}$ is the activation energy, $\mathrm{R}$ is the gas constant and $\mathrm{T}$ is the temperature. The apparent activation energy obtained for both fibers are respectively, $202 \mathrm{~kJ} \mathrm{~mol}^{-1}$ and $145 \mathrm{~kJ} . \mathrm{mol}^{-}$ ${ }^{1}$ for the ZMI and Nicalon fiber. 


\subsection{Chlorine reactivity}

An elemental composition analysis has been first performed for both fiber, using an electron probe micro analyser, in order to understand their different reactivity towards chlorine.

Results have evidenced zirconium traces in the ZMI fiber, which is a well known characteristic of this fiber [14]. Yet, the major difference between both fibers resides in the oxygen atomic concentration which is higher in the case of Nicalon fiber. In the temperature range $550-675^{\circ} \mathrm{C}$, chlorine is not supposed to react with carbon. Besides, similar experiments conducted on bulk crystalline $\mathrm{SiC}$ samples have shown that their reactivity towards chlorine was significantly lower than that of the SiC-based fibers. On the other hand, no reaction between pure silica and chlorine should be expected under similar conditions. The high reactivity of the $\mathrm{SiC}$-based fiber should therefore be related to the presence of mixed tetrahedral environments $\mathrm{SiO}_{\mathrm{x}} \mathrm{C}_{(4-\mathrm{x})}(0 \leq \mathrm{x} \leq 4)$ in the amorphous oxycarbide phases [15]. As a matter of fact, it has been shown that the introduction of oxygen atoms induces a distortion of the Si tetrahedral environment as well as a polarization effect due to the high electronegativity of oxygen [16-17]. These two phenomena are therefore likely responsible for the increase of reactivity of the $\mathrm{SiO}_{\mathrm{x}} \mathrm{C}_{(4-\mathrm{x})}$ sites with the oxygen content (i.e. $\mathrm{x}$ ).

As a conclusion, the Nicalon fiber which contains the highest oxygen concentration in Si-O-C amorphous phase, logically exhibits the highest chlorine reactivity, which is besides in accordance with the fact that thus fiber had the lower calculated apparent activation energy.

\subsection{Carbon coating characteristics}

Atomic force spectroscopy analyse have been conducted in order to obtain a morphological characterization of the fiber surface at an extremely low scale. Figure 6 
displays the results of AFM analyse performed on a desized ZMI fiber, as well as on two ZMI fibers which had been chlorinated at two different temperatures (550 and $\left.600^{\circ} \mathrm{C}\right)$.

These results show that the chlorination treatment has generated a nano-range roughness on the extreme surfaces, which besides tends to increase with the temperature treatment. In a next step, the carbon coatings porosity and specific surface area (SSA) have been characterized by nitrogen adsorption analysis. Figure 7 thus displays an adsorption and desorption isotherm obtained on Nicalon fibers having a carbon coating thickness of $1 \mu \mathrm{m}$. This investigation was carried out through three parameters, namely the evolution of the SSA calculated using BET equation, the pore volume and the slit pores size distribution calculated using semi-empirical HK approach. After gas sorption analysis, each sample was oxidized at $500^{\circ} \mathrm{C}$ under pure oxygen atmosphere using a TGA apparatus in order to first determine the weight percent of carbon coating and then to estimate the SSA and pore volume per gram of carbon coating. This isotherm curve presents a type I form, revealing the existence of micropores $\left(\varnothing_{\text {pore }}<2 \mathrm{~nm}\right)[18]$. Besides, the determination of the carbon weight leads to a carbon coating SSA value of about $1600 \mathrm{~m}^{2} \cdot \mathrm{g}^{-1}$.

It has also been found that an increase of the chlorine etching temperature led to higher SSA and pore volumes (table 2). This may be related to the fact that, for a constant volume of fiber, the increase of temperature led to a higher carbon extraction during the chlorine-based treatment. This last phenomenon may be explained with a thermodynamic simulation of the chlorine-based treatment.

It may thus be ascertained, from figure 8 , that for temperatures lower than $600^{\circ} \mathrm{C}$, oxygen localized in the fiber reacts with carbon to produce carbon dioxide $\left(\mathrm{C}(\mathrm{s})+\mathrm{O}_{2}(\mathrm{~g})=\right.$ $\left.\mathrm{CO}_{2(\mathrm{~g})}\right)$. Conversely for temperatures higher than $600^{\circ} \mathrm{C}$, the predominant reaction becomes the carbon monoxide formation $\left(2 \mathrm{C}(\mathrm{s})+\mathrm{O}_{2(\mathrm{~g})}=2 \mathrm{CO}(\mathrm{g})\right)$. These results therefore 
tend to show that, for temperature treatments higher than $600^{\circ} \mathrm{C}$, the extraction of oxygen consumes more carbon, resulting thus in a higher pore volume.

\subsection{Characterization and suppression of the carbon coatings contamination}

TGA experiments were achieved under argon atmosphere with a ramping rate of $20^{\circ} \mathrm{C} \cdot \mathrm{min}^{-1}$ up to $1300^{\circ} \mathrm{C}$, in order to degas the carbon coatings. The weight loss evolution derived from these tests presents two interesting temperature domains, 200400 and $550-1300^{\circ} \mathrm{C}$, corresponding respectively to a weight loss of 2 and $23 \mathrm{wt} \%$. XPS and mass spectrometry analyses were performed on Si-O-C fibers totally transformed into carbon fibers (with a chlorine-based treatment applied at $680^{\circ} \mathrm{C}$ for 45 minutes), in order to determine the nature of the species responsible for these weight losses. Figure 9 presents an XPS spectrum obtained from a carbon derived ZMI fiber surface. Two peaks correspond to chemisorbed chlorine (200 and $201.5 \mathrm{eV}$ ), whereas oxide and nitride functions are also detected at the carbon surface in lower quantity. Figure 10 presents the mass spectrometry results obtained for the same sample. Results have shown that these carbon fibers entirely derived from SiC-based fibers contain approximately $23 \mathrm{wt} \%$. contaminants, principally chemisorbed chlorine, but also oxide and nitride functions. It has also been found that, in order to degas small coatings (smaller than $1 \mu \mathrm{m}$ ), it was sufficient to perform heat treatments under argon at $700^{\circ} \mathrm{C}$ during one hour. Nevertheless, degassing higher coating thicknesses needed higher temperature treatments, up to $1100^{\circ} \mathrm{C}$ for an entire transformation into carbon fibers. Regarding the temperature domain the various volatile species released by SiC-based transformed carbon fibers, three main domains may be observed. The first one concerns aliphatic radicals released between ambient temperature and $350{ }^{\circ} \mathrm{C}$, the second one concerns other aliphatic radicals released between $350^{\circ} \mathrm{C}$ and $700^{\circ} \mathrm{C}$. These first two domains may be connected with the first step of weight loss (i.e. 2 wt $\%$ ) which are 
observed in the thermogram displayed in figure 10. The third domain only concerns chlorine thermal desorption occuring between $500^{\circ} \mathrm{C}$ and the maximum temperature analysis $\left(950^{\circ} \mathrm{C}\right)$. This last domain may be connected with the second step of weight loss (23 wt \%) observed in figure 11. It should also be pointed out that small quantities of carbon oxide $\left(\mathrm{CO}, \mathrm{CO}_{2}\right)$ were released during analysis revealing therefore a poor functionalization of carbon surface by oxygen group during process and / or storage.

\subsection{Oxidation behavior}

The oxidation behavior of the various carbon coatings has been investigated, after decontamination, by thermogravimetric analysis (TGA) under oxygen atmosphere for a temperature range of $225-400^{\circ} \mathrm{C}$.

The results have shown that these carbon coatings were prone to oxidation since $225^{\circ} \mathrm{C}$ (a relatively low temperature for carbon oxidation) with an apparent activation energy of about $120 \mathrm{~kJ} \mathrm{~mol}^{-1}$ which is close to the values reported so far in the literature [19]. This premature oxidation susceptibility of the carbon coatings can be explained by (i) their microporosity coupled with a high specific surface area and (ii) their disordered aspect, as observed by TEM. Thus, the TEM 002 dark field image of one of these carbon coatings exhibited in figure 12a shows a homogeneous phase with no preferential orientation, as confirmed by the uniform lightning of the carbon layer surrounding the fiber. The selected Area Diffraction pattern (SAD) was obtained selecting a $100 \mathrm{~nm}$ area in the middle of this carbon layer (figure 12b). This SAD pattern exhibits a broad and diffuse 002 peak with a maximum around $0.366 \mathrm{~nm}$, which is far larger than the $\mathrm{d}_{002}$ spacing usually found in graphite $(\mathrm{d}=0.336 \mathrm{~nm})$. Besides two dimensional lattice reflections 10 and 11 can be clearly seen on the diffraction pattern. Values of the size of the coherent domains along the c-axis, Lc, and of the diameter of these coherent domains, La10, were estimated as $1.7 \mathrm{~nm}$ and $5.5 \mathrm{~nm}$, respectively 
(obtained from the width of the 002 peaks and the 10 band). These results indicate that, inside these in-situ formed coatings, the atoms of carbon are organized into small aromatic domains, randomly oriented and poorly stacked.

\section{Conclusion}

Carbon coatings have been in-situ synthesized on the surface of two different SiC-based fibers by chlorine treatment in the temperature range $550-675^{\circ} \mathrm{C}$. Various characterizations conducted on this treatment as well as on the resulting carbon coatings have revealed interesting features. Among them and of major importance, it has been shown that homogeneous carbon coatings with a good adhesion to the fiber core can thus be performed on SiC-based fibers in the selected temperature range. It has also been shown that the growth of the carbon coatings follows linear kinetics involving a surface reaction mechanism, the reaction rate being related to the oxygen concentration of the Si-O-C amorphous phase. The NLM-202 Nicalon fiber $(\mathrm{O} \%=13.8)$ proved to be more prone to chlorine-based treatment than the Tyranno ZMI fiber $(\mathrm{O} \%=9.2)$, as

evidenced by a lower apparent activation energy $\left(\mathrm{Ea}\left(\mathrm{Ni}_{1}\right)=143 \mathrm{~kJ} \cdot \mathrm{mol}^{-1}, \mathrm{Ea}(\mathrm{ZMI})=210\right.$ $\mathrm{kJ} . \mathrm{mol}^{-1}$ ). The temperature of the chlorine-based treatment appeared to be essential in controlling the carbon coating porosity: the higher was the treatment temperature, the higher were the roughness, the specific surface area and the porosity of the resulting carbon coatings. However, both the porosity and the weak microstructural organization of these carbon coatings resulted in a low oxidation resistance (oxidation beginning at $\left.225^{\circ} \mathrm{C}\right)$.

\section{Acknowledgments}

The authors wish to thanks Muriel Alrivie for the preparation of the TEM samples, Michel Lahaye for the Auger spectroscopy analyses. The authors gratefully acknowledge the financial support of the ADEME and SPS for this work. 


\section{References}

1. K.N. Lee, R. A. Miller, J. Am. Ceram. Soc. 79 (1996) 620-626.

2. M. Shibuya, H. Yamaoka, K. Kumagawa, T. Yamamura, 9th Cimtec World Forum on New Materials - Symposium V - Advanced structural fiber composites Florence, Italy, Vincenzini P (Editor) - Techna Srl. 1999, pp. 63-70.

3. D.J. Pysher, K.C. Goretta, R.S. Hodder and R.E. Tressler, J. Am. Ceram. Soc. 72 (1989) 284-288.

4. A. Delcamp, L. Maillé, S. Saint Martin, R. Pailler, A. Guette, Comp. Sci. Technol. 70 (2010) 622-626

5. R. Naslain, J. Lamon, R. Pailler, X. Bourrat, A. Guette, F. Langlais International Symposium on Ceramic Matrix Composites, oct 28-30, 1997 Tokyo Japan, Composites part A-Applied science and manufacturing 30 (1999) 537-547

6. M.J. McNallan, Y. Gogotsi, D. Erosy, Reaction formed coatings for SiC fibers in ceramic matrix composites, Elevated temperature coatings:Science and Technology III. Edited by J. M. Hampikian and N.B. Dahorte, The minerals, metals and materials society (TMS), Warrendale, PA, 1999, pp. 351-359.

7. L. Chen, G. Behlau, Y. Gogotsi, M. J. McNallan, Ceram. Eng. Sci. Proc. 24 (2003) 57-62.

8. G. Cheng, D.H. Long, X.J. Liu, L.C. Ling, New Carbon Materials, 24 (2009) 243250

9. J. Chmiola, G. Yushin, R. Dash, Y. Gogotsi, J. Power Sources 158 (2006) 765 722

10. C. Portet, D. Kazachkin, S. Osswald, Y. Gogotsi, E. Borguet, Thermochimica Acta 497 (2010) 137-142

11. M. Balooch, D.R. Olander, Surf. Sci. 261 (1992) 321-334

12. S. Welz, M.J. McNallan, Y. Gogotsi, J. Mater. Proc. Technol. 179 (2006) 11-22

13. S. Brunauer, Ph. Emmett, E Teller, J. Am. Chem. Soc. 60 (1938) 309-

14. H. Yamaoka, T. Ishikawa, K. Kumagawa, J. Mater. Sci. 34 (1999) 1333-1339.

15. F. Babonneau, L. Bois, C.Y. Yang, L.V. Interrante, Chem. Mater. 6 (1994) 51-57.

16. F.I. Hurwitz, M.A.B. Meador, J. Sol-gel Sci. and Tech. 14 (1999) 75-86.

17. P. Kroll, J. Mater. Chem. 13 (2003) 1657-1668.

18. S. Brunauer, L.S. Deming, W.S. Deming, E. Teler, JACS 62 (1940) 1723-1732

19. I.W. Smith, Fuel 57 (1978) 409-414. 


\section{List of figure and table captions}

\section{Figure 1: Representation of the reactor used for chlorination}

Figure 2: Evolution of the carbon coating thicknesses as a function of the treatment duration at $600^{\circ} \mathrm{C}(\mathrm{a})$ and $650^{\circ} \mathrm{C}(\mathrm{b})$.

Figure 3: Cross-section SEM images obtained on chlorine-etched fibers at $600^{\circ} \mathrm{C} / 180 \mathrm{~min}, \mathrm{ZMI}$ fiber (a), Nicalon fiber (b).

Figure 4: Auger Electron Spectroscopy depth-profile of the ZMI fiber chlorine-etched at $600^{\circ} \mathrm{C} / 180 \mathrm{~min}$.

Figure 5: Arrhenius plots obtained for the two SiC-based fibers in the temperature range $550-675^{\circ} \mathrm{C}$.

Figure 6: AFM images obtained on desized ZMI fiber; as received (a), after chlorination at $550^{\circ} \mathrm{C}(\mathrm{b})$, and after chlorination at $600^{\circ} \mathrm{C}(\mathrm{c})$.

Figure 7: Nitrogen adsorption and desorption isotherms obtained on carbon- coated Nicalon fibers (thickness of about $1 \mu \mathrm{m})$.

Figure 8: Plots of the results of thermodynamic calculations for the amount of carbon at equilibrium as a function of the chlorine-etching temperature (at $1 \mathrm{~atm}$ ) [7].

Figure 9: XPS spectrum totally transformed in carbon ZMITM fibers.

Figure 10: Mass spectrometry spectra totally transformed in carbon ZMITM fibers

Figure 11: TGA under pure argon atmosphere with a temperature rate of $20^{\circ} \mathrm{C} \cdot \mathrm{min}^{-1}$. Figure 12: TEM 002 dark field image of the thick carbon coating surrounding the SiC fiber $\left(\mathrm{ZMI}{ }^{\mathrm{TM}}\right)(\mathrm{a})$ and SAD pattern of the carbon layer (b)

Table 1: WDS analysis of the two SiC-based fibers used in this study (in atomic percent).

Table 2: Evolution of the porosity as a function of the chlorine etching temperature. 
Figure 1

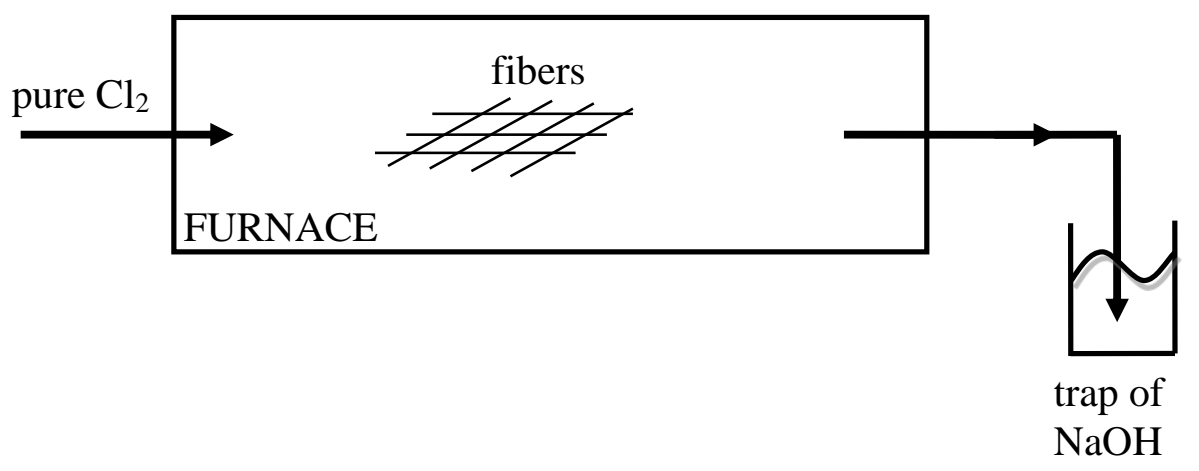




\section{Figure 2}
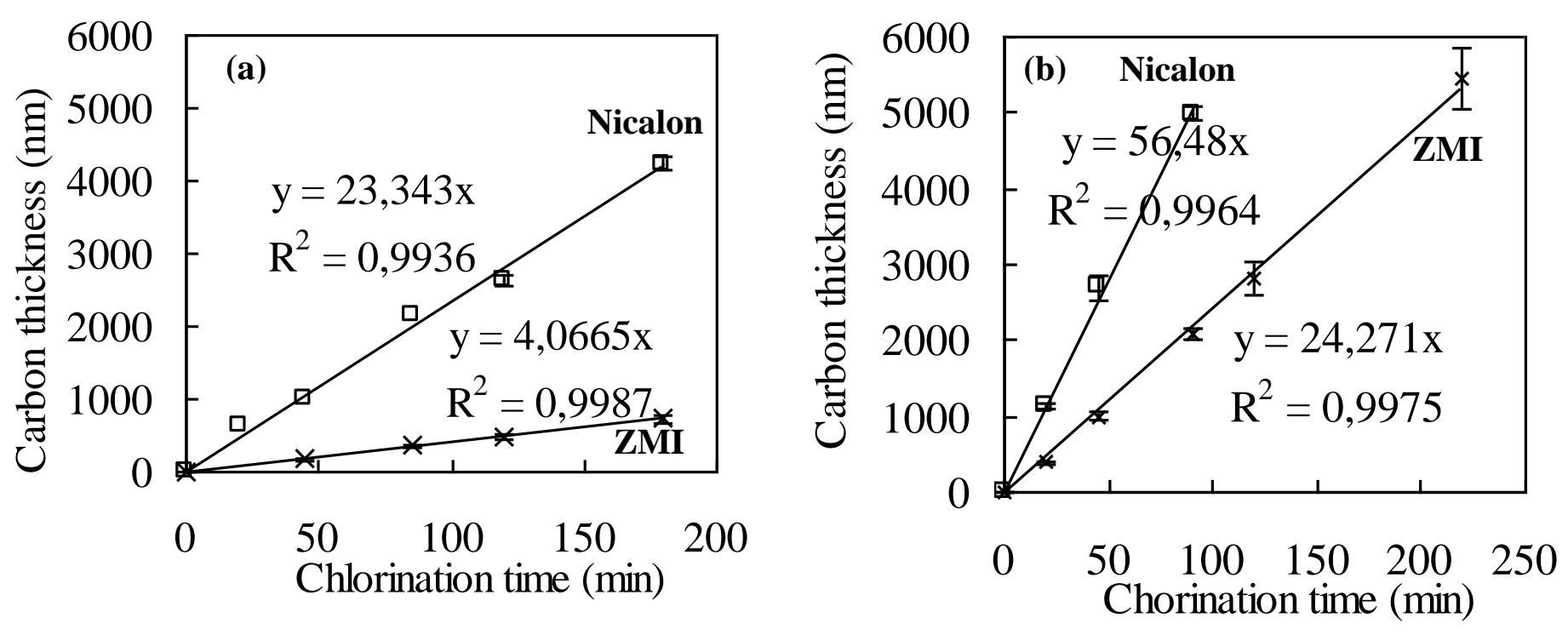

Figure 3
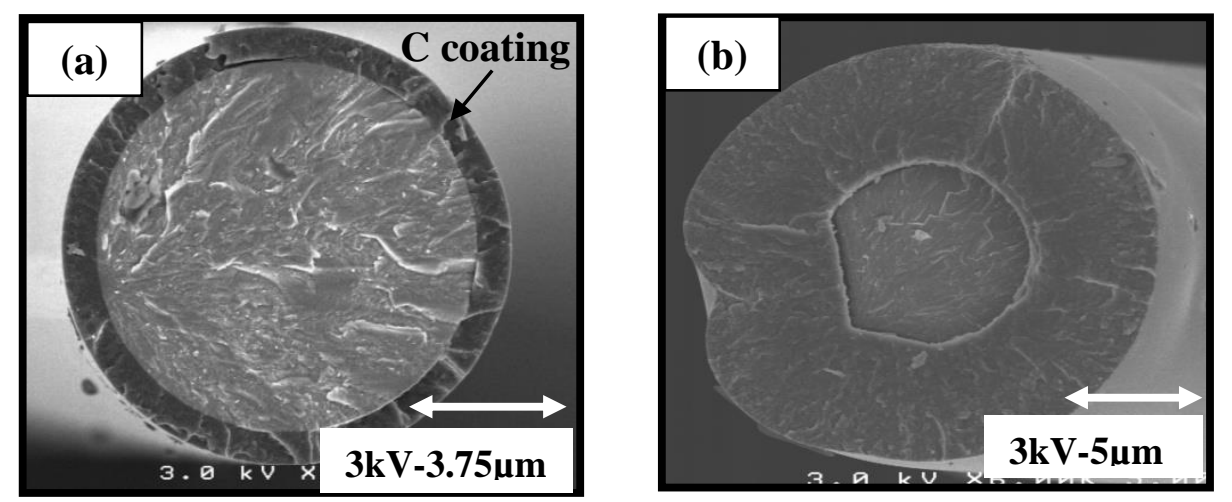


\section{Figure 4}

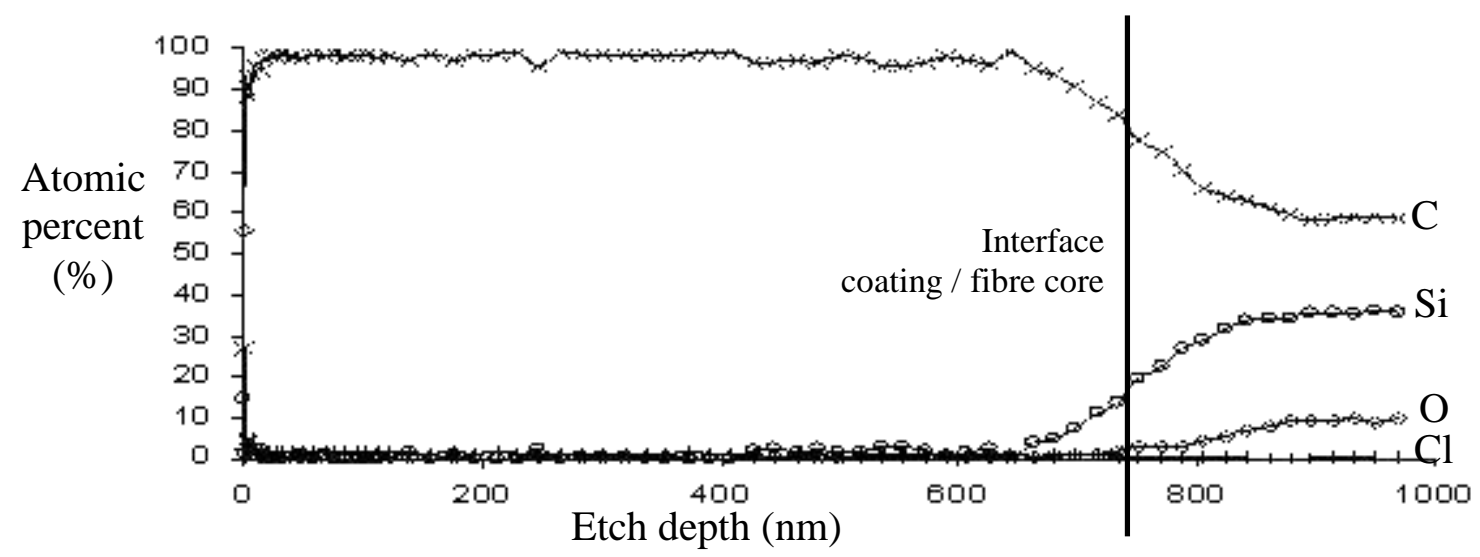

Figure 5

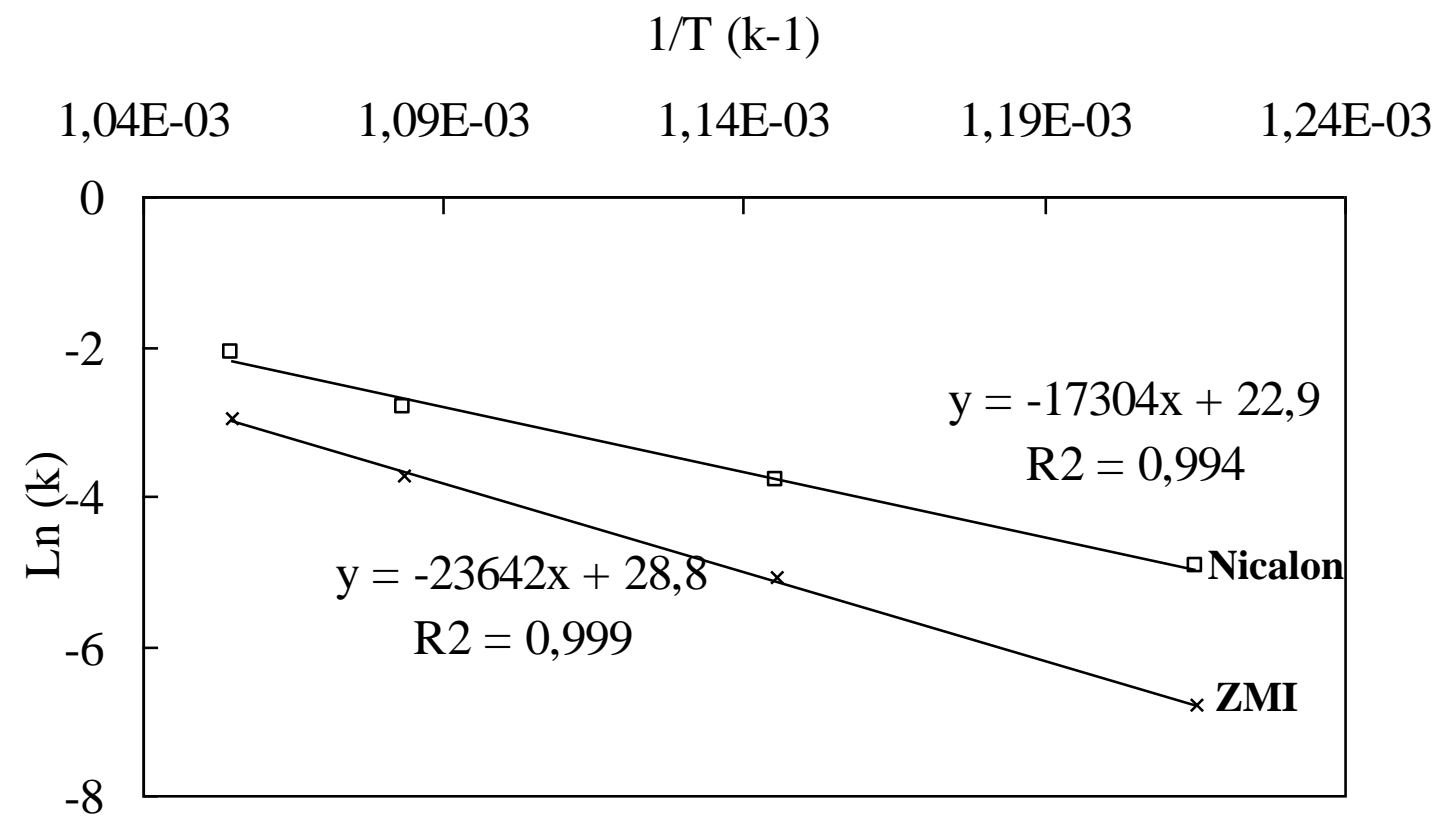




\section{Figure 6}

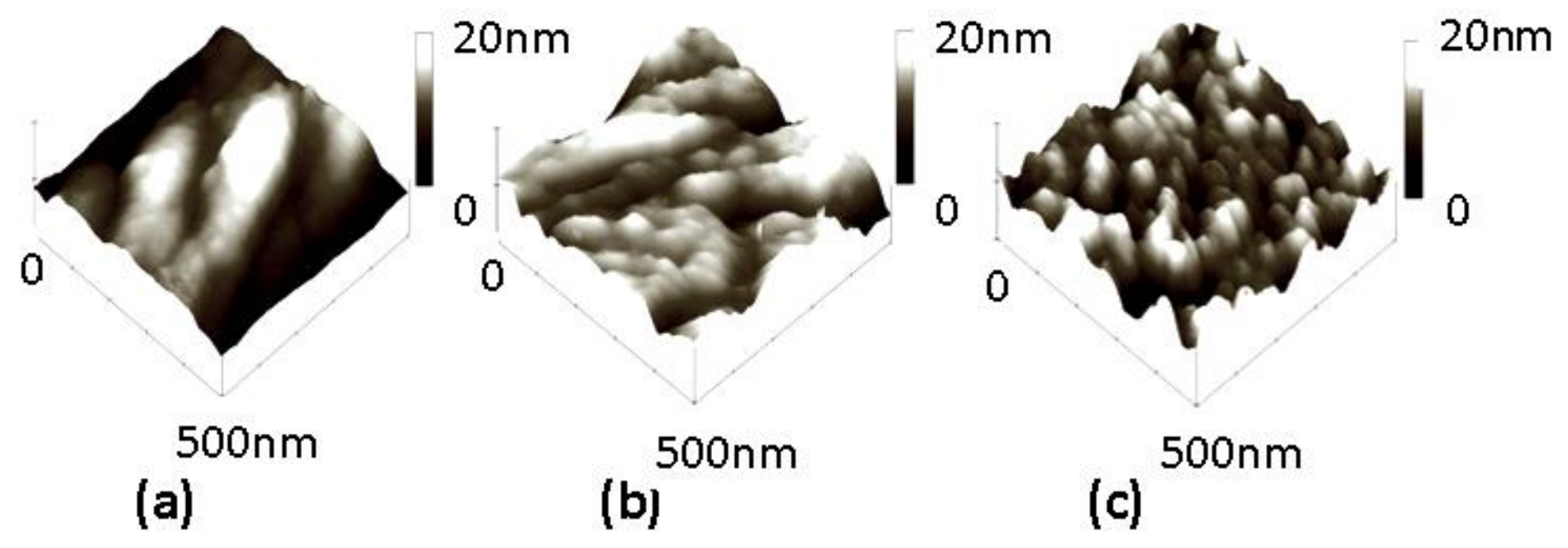

Figure 7

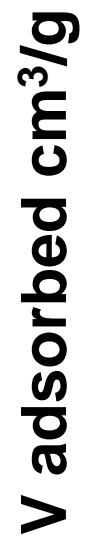

$p / p_{0}$ 


\section{Figure 8}

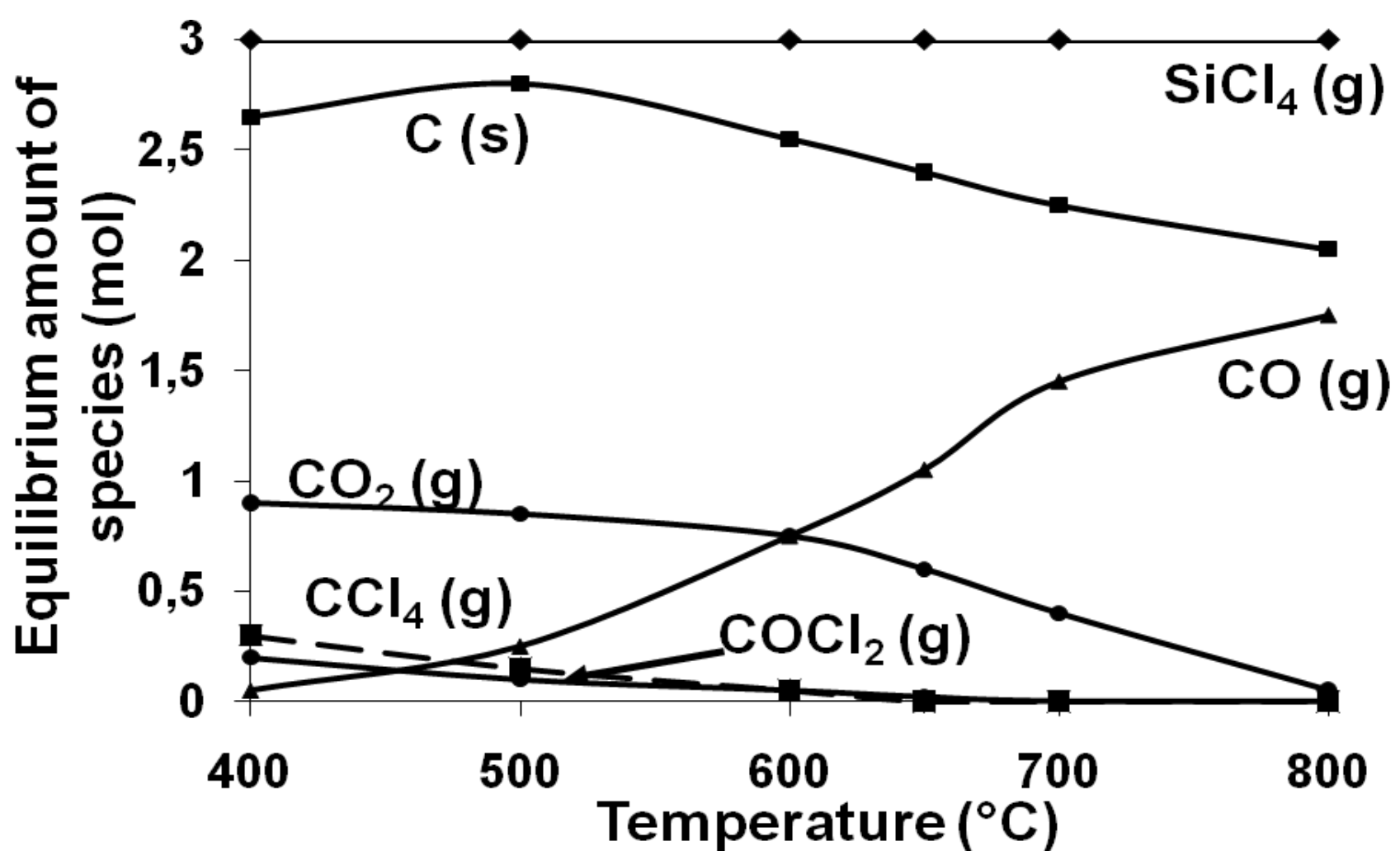

Figure 9

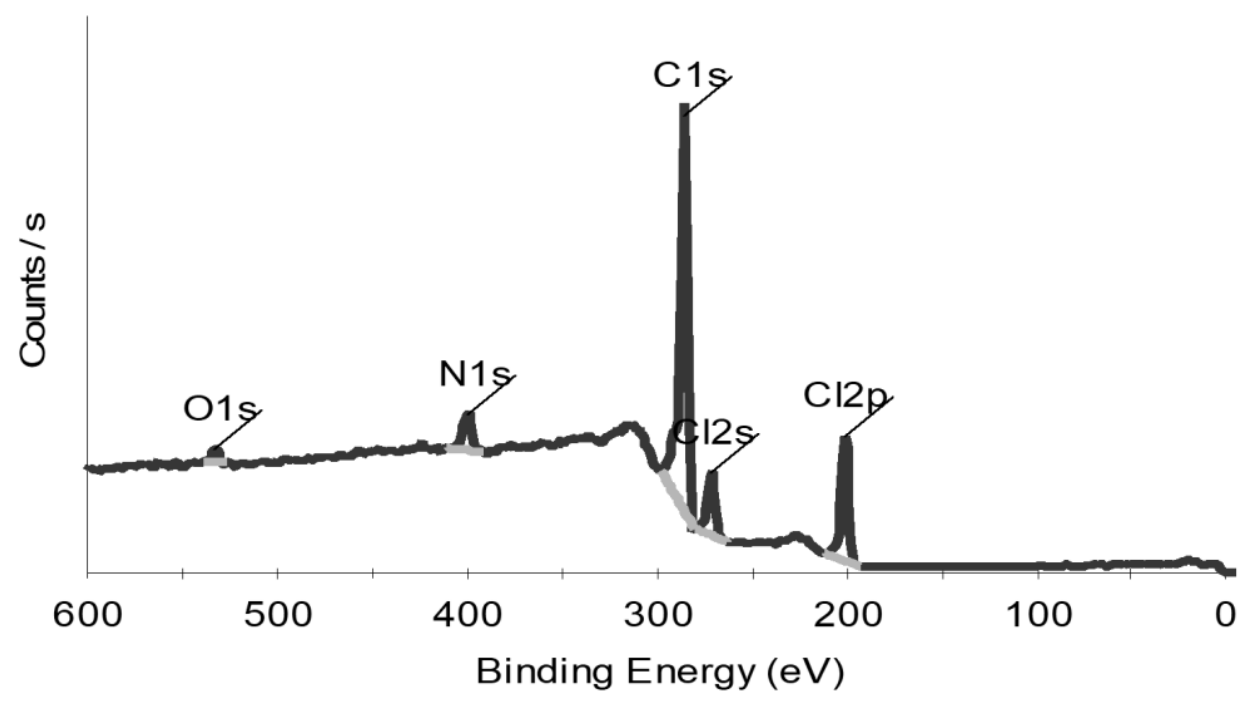




\section{Figure 10}

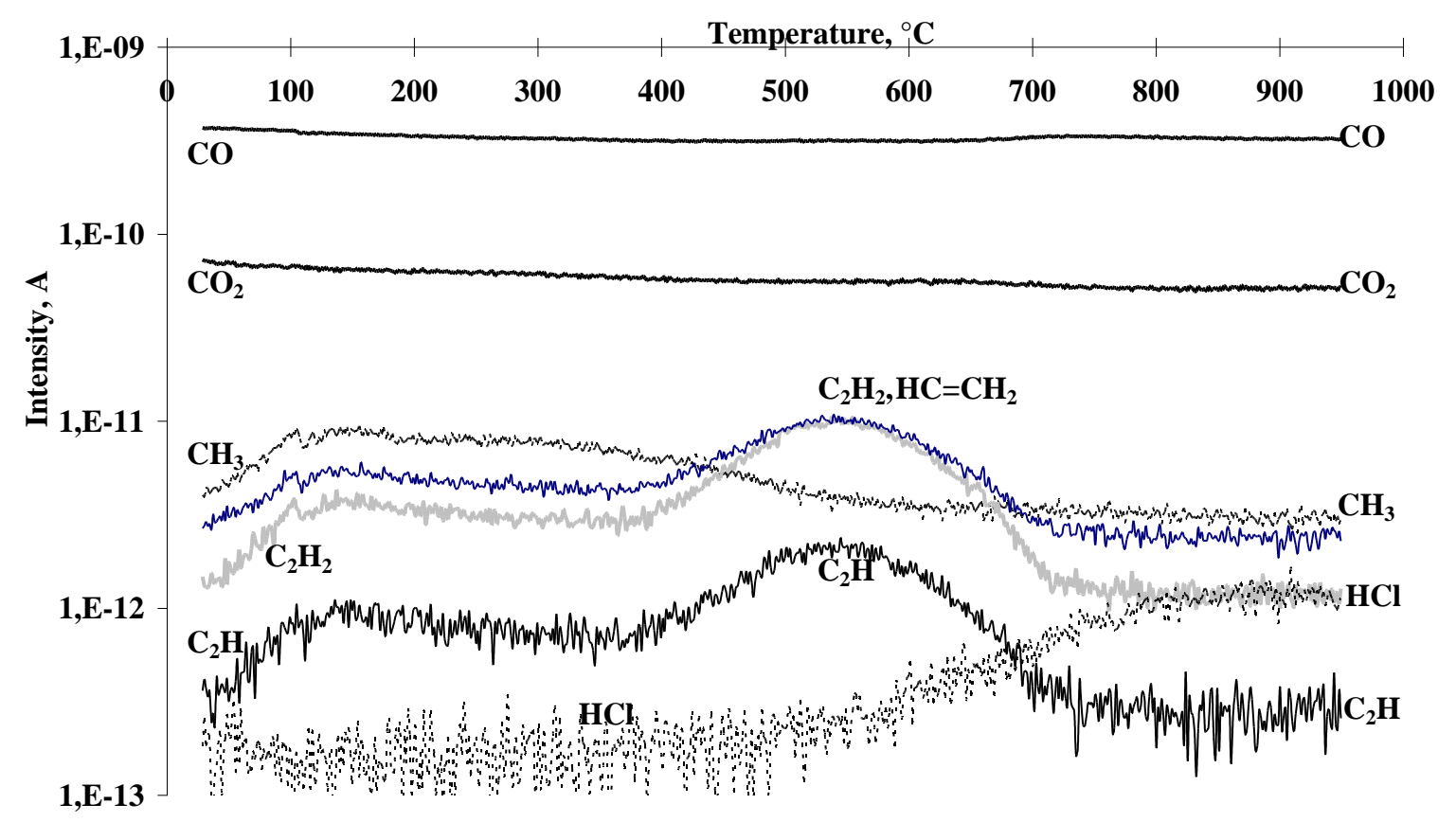

\section{Figure 11}


time (h)

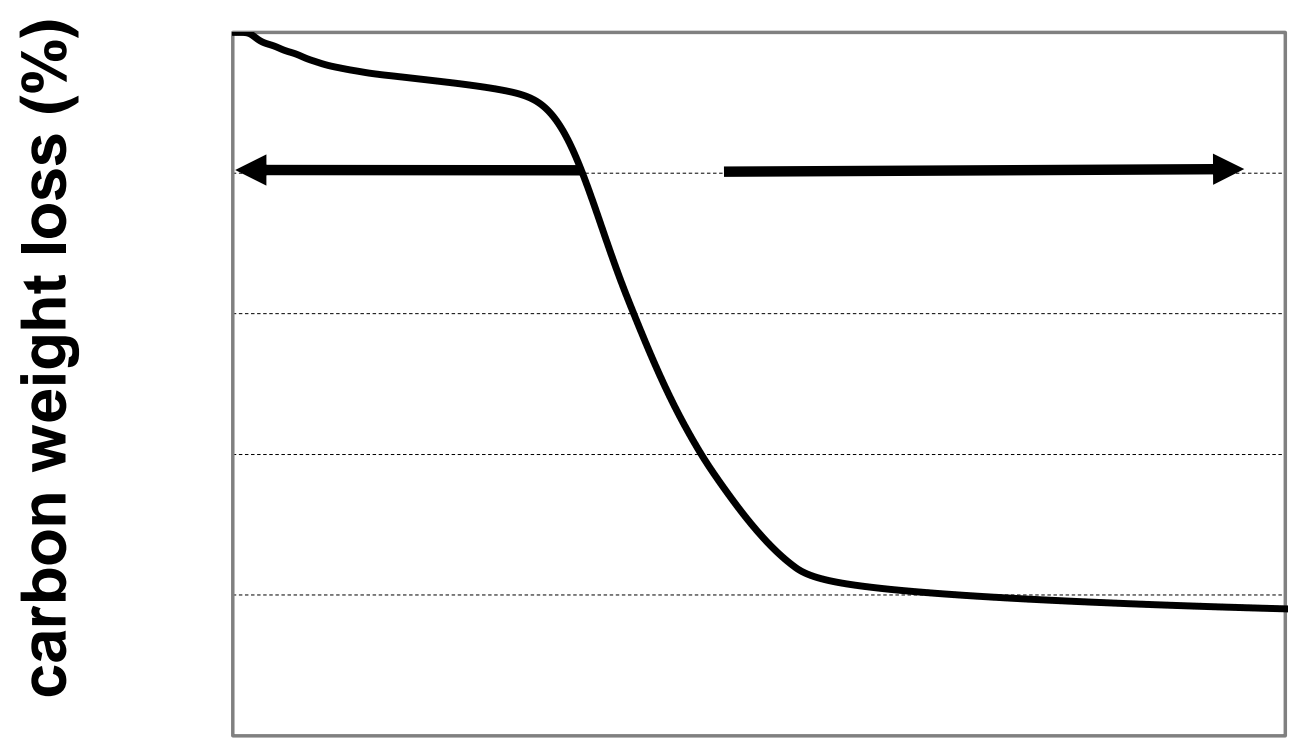

$\underbrace{0}_{1}$ 
Figure 12
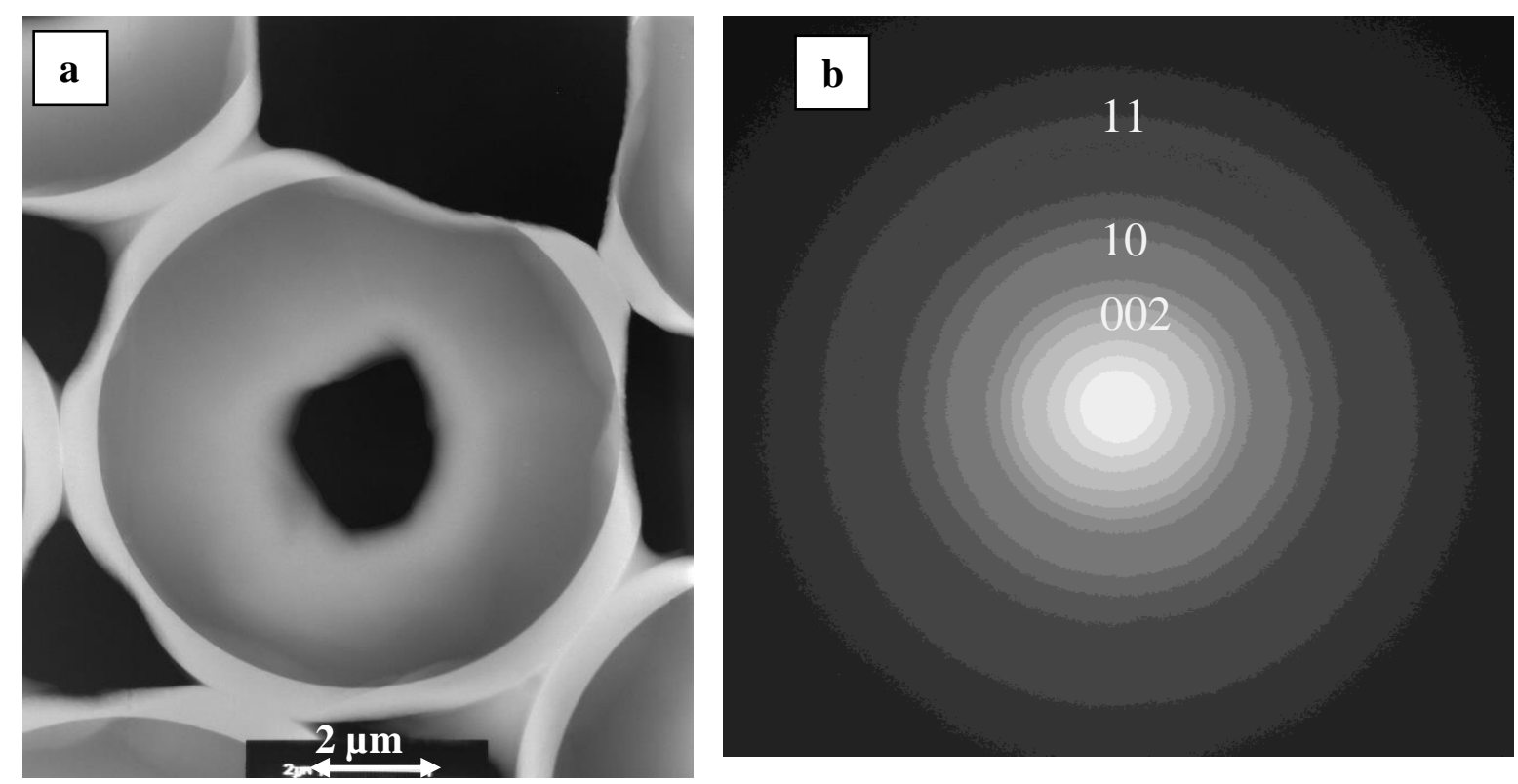


\section{Table 1}

\begin{tabular}{|c|c|c|c|c|}
\hline Fiber & Si & O & $\mathbf{C}$ & $\mathbf{Z r}$ \\
\hline ZMI & 35.6 & 9.2 & 55.0 & 0.2 \\
\hline Nicalon & 38.4 & 13.8 & 47.8 & 0 \\
\hline
\end{tabular}

\section{Table 2}

\begin{tabular}{|c|c|c|c|c|}
\hline Fibers & $\begin{array}{c}\text { Temp } \\
\left({ }^{\circ} \mathbf{C}\right)\end{array}$ & $\begin{array}{c}\text { SSA } \\
\left(\mathbf{m}^{2} / \mathbf{g}\right)\end{array}$ & $\begin{array}{c}\text { Pore volume } \\
\left(\mathbf{c m}^{\mathbf{3}} \mathbf{g}\right)\end{array}$ & $\begin{array}{c}\text { Pore diameter } \\
<\mathbf{2} \mathbf{~ n m}\end{array}$ \\
\hline ZMI & 650 & 1161 & 0.517 & $92 \%$ \\
\hline ZMI & 600 & 994 & 0.455 & $91 \%$ \\
\hline Nicalon & 675 & 1580 & 0.697 & $94 \%$ \\
\hline Nicalon & 650 & 1214 & 0.54 & $89 \%$ \\
\hline Nicalon & 600 & 838 & 0.381 & $89 \%$ \\
\hline Nicalon & 550 & 585 & 0.280 & $88 \%$ \\
\hline
\end{tabular}

